CIENCIA Y SOCIEDAD

Volumen XXII, Número 3

Julio-Septiembre 1997

PROPUESTAS PARA LA PARTICIPACION SOCIAL EN LOS GOBIERNOS MUNICIPALES

Pedro A. Hernández

\title{
La representación política
}

La Constitución dominicana establece en el artículo dos correspondiente a la sección sobre la Nación, la Soberanía y el Gobiemo, que "la soberanía nacional corresponde al pueblo, de quien emanan todos los poderes del Estado, los cuales se ejercen por representacion".

El artículo cuatro de la misma sección de la Constitución establece, por su parte, que "el gobierno de la Nación es esencialmente civil, republicano, democrático y representativo.

La Constitución divide el Estado en poder Legislativo, Ejecutivo y Judicial, los cuales se ejercen por representación. También los ayuntamientos, que son considerados gobiernos municipales, se ejercen por representación.

La Constitución y la Ley Electoral dominicanas no son explícitas respecto al ejercicio de la representación políticas, pero de acuerdo con el derecho de nominación de candidaturas, los senadores, diputados, síndicos y regidores son representantes de sus respectivos partidos y no de los ciudadanos que los eligen.

Al respecto, el artículo 78 de la Ley Electoral dice: "todo partido político que esté reconocido de conformidad con la presente ley tiene el derecho de proponer candidatos a cualesquiera cargos electivos que hayan de cubrirse, siempre que se ciña a los requisitos, formalidades y plazos que para ello se establecen". 
Los partidos políticos reconocidos por la Junta Central Electoral tienen, exclusividad de nominación de candidaturas para los y las representantes nacionales, provinciales y municipales.

Los senadores y diputados en el Congreso, y los síndicos y regidores en las salas capitulares de los ayuntamientos, son delegados de los partidos, y sus actuaciones y comportamientos están vinculados al mandato partidario, no al mandato popular o ciudadano.

La mejor prueba de esto es la existencia de los llamados "bloques" de senadores y diputados, los cuales velan porque las posiciones tomadas por cada uno de los legisladores miembros de dichos "bloques" estén acorde con las líneas políticas del partido correspondiente.

Toda decisión que tome un senador, diputado o regidor, se toma como previamente decidida en su partido, y viceversa, toda decisión de índole política tomada en el partido, compromete a los senadores, diputados o regidores de ese partido, aunque ellos, individualmente, no estén de acuerdo con la decisión.

Los senadores, diputados o regidores no tienen autonomía e independencia, pues actúan de acuerdo con la voluntad política de los partidos. ${ }^{1}$

\section{Las agrupaciones accidentales}

También las agrupaciones políticas "accidentales", según las denominas la Ley Electoral, tienen derecho a proponer candidaturas independientes de carácter nacional, provincial y municipal.

Pero la Ley Electoral exige a las llamadas agrupaciones políticas "accidentales" un por ciento más alto de miembros o afiliados, para ser reconocidas jurídicamente y obtener el derecho de nominación de candidatos.

1 Para una mayor y mejor comprensión sobre la representación y la delegación de la soberanía popular en los partidos, véase el texto: Teoría y sociología crítica de los partidos políticos. De Kur Lenk y Frank Neuman. Editorial Anagrama. Barcelona, España. 1980. También: Crisis de legitimidad y democracia interna de los partidos políticos. De Jaime F. Cárdenas Gracia. Fondo de Cultura Económica. México. 1992. 
El Artículo 87 de la Ley Electoral No. 5884 determina que cuando el número de inscritos en el registro electoral de un municipio sea de 5 mil electores o menos, las agrupaciones accidentales necesitan tener como adherentes o afiliados el 20 por ciento de esos inscritos, para ser reconocidas.

Si el registro electoral del municipio es de más de 5 mil personas y menos de 20 mil, las agrupaciones accidentales que se formen necesitan demostrar que tienen como afiliados el 15 por ciento de esos inscritos, para ser reconocidas y tener opción a las representaciones municipales.

Si el registro electoral municipal es de más de 20 mil y menos de 60 mil personas la exigencia es, entonces, de un 12 por cientos. Y si es de más de 60 mil, las organizaciones accidentales requieren, entonces, el 7 por ciento de los inscritos como adherentes o afiliados, para ser reconocidas y tener derecho a nominar candidatos y participar en las elecciones congresionales y municipales.

La Ley Electoral No. 5884, que data del 5 de mayo de 1962, fue ligeramente modificada por la Ley No. 11-95, pero las condiciones para tener derecho a presentar candidaturas independientes perma necen iguales.

Lo que más llama la atención al respecto, es que cursa en el Congreso nacional un proyecto de reforma a la Ley Electoral presentado por la Junta Central Electoral, y en dicho proyecto las condiciones para poder presentar candidaturas independientes no se modifican no obstante constituir una traba para que la ciudadanía pueda ejercer el derecho a ser elegida.

De manera, que la Ley Electoral exige que las agrupaciones accidentales sean orgánica e institucionalmente iguales a los partidos políticos nacionales, para otorgarles el derecho a optar por tener representantes congresionales y municipales.

Eso significa, que sólo a través de los partidos políticos los ciudadanos están en condiciones de concertar sus voluntades políticas.

Eso es ignorar la realidad social del país.

A partir de 1961 y quizás hasta la década de los 80 , los partidos políticos fueron los instrumentos a través de los cuales los ciudada- 
nos agregaron y canalizaron sus demandas democratizadoras de libertad, justicia social y participación política frente al listado, pues los partidos canalizaban la globalidad de las demandas ciudadanas, entre otras causas, porque las demás instituciones de la sociedad civil eran aún muy débiles o inexistentes.

Pero los partidos se han convertido en espacios organizativos de interacción colectiva limitada y restringida, en simples maquinarias electorales para la promoción hacia el Estado de los miembros que logran escalar sus estructuras jerárquicas, y poco a poco han estado dejando de representar y canalizar las demandas ciudadanas.

De ahí que muchos cientistas sociales (entre los que me incluyo) planteen que los partidos políticos dominicanos no pertenecen a la sociedad civil, pues han devenidos en efectivos organos auxiliares del Estado en la medida su interés está centrado en insertarse en las estructuras del poder político.

Un autor sostiene al respecto, que los partidos políticos colaboran en la estructuración del gobierno y en los mecanismos de sucesion, seleccionan la clase política gobemante al monopolizar la designación de candidaturas, integran relaciones institucionales con organos del Estado; participan en la integración del aparato estatal al fiscalizar el proceso; son permanentes alimentadores de opinión públicas y creadores a largo plazo de programas de gobierno, plataformas políticas y formación política ciudadana. ${ }^{2}$

La democracia que se basa solamente en los partidos como agrupaciones que canalizan la representación es el reino de los militantes partidarios.

Por eso, los partidos han sido desbordados por una variedad de nuevas demandas territoriales, de género, ecológicas, de clases y otras, que son canalizadas ahora por una diversidad de mediaciones u organizaciones sociales.

Con la realización de estas acciones, las organizaciones de la sociedad civil van borrando las viejas distinciones entre lo político y lo social.

2 Jorge Mario García Laguardia. Régimen constitucional de los partidos políticos en Centroamérica: De la exclusión a la apertura En Sistemas Electorales y Representación Política en Latinoamérica. Volumen No. 1. Fundación Friedrich Ebert. Madrid. 1986. Págs. 211-212. 
Ya la democracia no sólo descansa en los partidos, existen otras organizaciones que actúan independientemente de los partidos políticos y a través de las cuales los ciudadanos se sienten socialmente representados.

De manera que ya la política no es un asunto exclusivo de los partidos, aunque los partidos continúan siendo instancias importantes del sistema.

Circunscribir la representación política exclusivamente con los partidos, es una forma de crear un sistema político oligopólico que limita la representación y la participación de la ciudadanía en los circuitos políticos de tomas de decisiones.

\section{Lo político y lo social:}

La constitución de lo político se manifiesta en diversos espacios, por lo tanto, no se puede hablar de la esfera de la política en singular, sino más bien en distintos circuitos de intercambio de lo político. ${ }^{3}$

La política no se reduce al Estado y a los partidos, la política también se juega en la sociedad civil, y la sociedad civil se ha estado organizando independientemente de los partidos y de todas las instituciones formales.

Ahí está la irrupción de los nuevos movimientos sociales, de organizaciones vecinales y comunitarias, de ONGs y de otras formas de agregación social, para confirmar que lo político tiene cada vez más una dimensión social y territorial.

$\mathrm{Al}$ respecto, en una investigación realizada en los barrios de la zona norte de la ciudad capital, Vanna lanni encontró que en los pobladores existe disposición a participar en el sistema político a través de formas delegativas (los partidos), pero también a protagonizar acciones reivindicativas en el lugar de trabajo y en el territorio, que traspasen el marco normativo e institucional existente. ${ }^{4}$

En otra investigación, realizada por la oficina de FLACSO en

3 Silvia Bolos. Citada por César Pérez en la Introducción del libro; Las organizaciones de base en Santo Domingo. De Tahira Vargas. Edición del Centro de Estudios P. Juan Montalvo. S.J. Santo Domingo. 1994.

4 Vanna Ianni. Una mirada a la cultura política dominante. Periódico El Siglo. Santo Domingo. 8 de marzo de 1990. 
República Dominicana, el 87.3 por ciento de los encuestados consideró que debe dársele más participación a las organizaciones barriales. El 50 por ciento de los mismos encuestados coincidio en señalar que la participación debe canalizarse a través de las organizaciones barriales. ${ }^{5}$

Es que existen dos escenarios posibles de construcción democrática. Uno está basado en la representatividad y el otro en la participación directa.

En el primer escenario, el Estado y los partidos, como instituciones políticas por excelencia, asumen la representación de las necesidades y demandas ciudadanas por delegación. En este caso, los ciudadanos ejercen la participación a través de las elecciones. En el segundo escenario actúa la sociedad civil a través de su conjunto de actores sociales organizados. ${ }^{6}$

En este ámbito se consideran todos aquellos aspectos relacionados con las organizaciones de la sociedad civil, sus actividades, objetivos e interrelaciones, y estaría conformado por un conjunto de organizaciones que canalizan intereses ciudadanos colectivos, pero locales, sectoriales, parciales o corporativos.

En este enfoque la sociedad civil alude a una vasta trama de asociaciones, instituciones y normas que conforman un tejido social y una comunidad política previa a la organización estatal.

Esta visión, que es la que compartimos, plantea que lo político y lo social son dos expresiones de un mismo proceso, como dos caras de una misma moneda, y se construyen en un proceso único y simultáneo.

De acuerdo con esta visión la sociedad civil y la sociedad política no son dos instancias ajenas una de la otra, sino por el contrario, partes de un todo en permanente interacción y complementariedad.

Ahora bien, en nuestro sistema político se aborda lo social y lo político como dos ámbitos distintos y separados.

En el ámbito de lo político se considera todo aquello que cae

5 Carlos Dore Cabral. Los dominicanos participan políticamente más que los haitianos. Revista Rumbo No. 96. Santo Domingo. 4 de diciembre de 1995. Págs. 44 y 45.

6 Eugeria Hola y Gabriela Pischedda. Mujeres, poder y política: nuevas tensiones para viejas estructuras. Centro de Estudios de la Mujer. Santiago de Chile. 199 . Pág. 52. 
dentro de los espacios de poder y decisión público o estatal, sea a nivel local, regional o nacional.

Y lo social se considera como todo aquello que pertenece estrictamente a la esfera de lo privado, de lo individual.

En esta consideración, por sociedad civil se entiende todo aquello que está enmarcado en el ámbito de las relaciones de mercado, en particular, la iniciativa empresarial.

En esta perspectiva, fortalecer la democracia no es sinónimo de ampliar los espacios públicos de tomas de decisiones con la incorporación de nuevos sujetos sociales, sino liberar las iniciativas privadas o empresariales de cualquier control o vigilancia estatal.

Una cosa debe quedar clara, nosotros no limitamos la política a lo estatal, de ahí que cuando decimos que la sociedad civil y la sociedad política son dos partes de un todo en permanente interacción y complementariedad, no estamos diciendo que lo social forma parte, necesariamente. de lo estatal. Por ejemplo, en el caso de las organizaciones comunitarias, su intervencion en las decisiones políticas no significa que ellas pasen a formar parte del Estado, ese no es su objetivo.

\section{Formación de organizaciones sociales}

Desde el siglo pasado se han estado formando en el país organizaciones sociales que se definen y actúan de forma independiente de los partidos políticos y de los gobiemos.

Entre esas organizaciones se destacan los clubes, los gremios y sindicatos, las organizaciones filantrópicas (ONGs), y otras de carácter territoriales y corporativas.

En un estudio acerca de la sociedad civil en el siglo pasado, el profesor José Antinoe Fiallo encontró documentadas innumerables organizaciones sociales urbanas, entre ellas: religiosas, patrióticas, políticas, de beneficencia, de omato, recreativas, de desarrollo, culturales, educativas y otras. ${ }^{7}$

7 José Antinoe Fiallo Billini. Nacionalismo y liberalismo: Recuperación de su pensamiento y su organización para la construcción de una estrategia popular. Mimeo. Universidad Autónoma de Santo Domingo. 1995. 
Varios factores contribuyen a la formación de organizaciones sociales, entre ellos:

Las informaciones que a través de los medios de comunicación reciben los ciudadanos y ciudadanas.

La convivencia en un mismo entorno geográfico o comunitario y el desarrollo en el mismo de una identidad cultural y de clase.

La experiencia organizativa y de lucha ganada por los pobladores en su vida cotidiana o aportada por ONGs y organizaciones vecinales y territoriales.

Las relaciones excluyentes que los partidos políticos establecen con los no militantes.

Y en los últimos años el hecho de que las condiciones de trabajo y la calidad de vida de los ciudadanos se haya deteriorado de tal manera que los haya obligados a buscar estrategias inmediatas de sobrevivencia.

Muchas de estas estrategias de sobrevivencia son de carácter individual, pero otras pasan por experiencias de luchas colectivas que determinan formas de organización que llegan a convertirse en aprendizaje político en la medida se conocen y se profundizan los conocimientos acerca de los derechos ciudadanos.

De esta base de conocimiento político y experiencia organizativa surgen en momentos específicos comités de lucha y redes de coordinación que se convierten coyunturalmente en espacios y mecanismos de representación social. Son modos de representación transitorios que tienen roles decisivos en momentos políticos y sociales específicos, por ejemplo, durante un paro o una huelga.

Se trata de formas de auto organización popular que surgen en función de reivindicaciones colectivas: empleo, precios de los artículos de primera necesidad, salud, educación, transporte y otros servicios básicos.

Es que la representación no es eficaz si no se arraiga en espacios y mecanismos en los cuales los ciudadanos se sientan involucrados y sean tomados en cuenta.

Ese es el problema de la representación monopolizada u oligopolizada por los partidos políticos, que se circunscribe a la "clase política” y deja fuera la intervención de la mayoría. 
Por eso, la democratización del actual sistema político requiere superar el actual modelo oligopólico de representación y participación política, ampliando sus bases con el otorgamiento a las organizaciones populares de un status jurídico que les reconozca derecho de intervenir y de estar representadas en los mecanismos públicos de toma de decisiones.

\section{Organizaciones sociales y partidos:}

Para evitar confusión y el peligro de que las organizaciones sociales compitan con los partidos y terminen como estos absorbidas por el Estado, se debe tener en cuenta que cuando se habla de participación de las organizaciones sociales se habla de formas muy particulares de participación.

Se trata de organizaciones barriales o campesinas que buscan defender intereses comunitarios específicos, no generales.

Son organizaciones que representan grupos de ciudadanos(as) muy concretos que se autoorganizan en estos núcleos sociales para canalizar sus demandas mediante su propia voz, sin intermediación.

Mientras los partidos políticos, teóricamente, asumen la defensa de la globalidad de los problemas y de las demandas sociales, las organizaciones sociales: barriales, populares, comunitarias y corporativas asumen sólo parte muy concreta de esa globalidad.

Eso está muy claro en las definiciones estatutarias y en los objetivos de las organizaciones comunitarias, y esa precisión es lo que permite que estas organizaciones operen como grupos primarios en los cuales predominan las relaciones directas y se conserven los sentimientos de afectos, de ayuda y solidaridad mútua entre los miembros, lo que a su vez facilita un intercambio de información más fluido, un diálogo permanente, alto niveles de transparencia y mayor grado de igualdad para ejercer el poder de decisión en los asuntos que conciemen a los asociados.

Dadas esas consideraciones, no es posible considerar que estas organizaciones tengan la misma categoría política y, por consiguiente, el mismo nivel de representatividad en el sistema político que los partidos, pero tampoco es posible considerar que no tienen ningún carácter representativo, como es en la actualidad. 
Lo más importante de las organizaciones comunitarias reside en el hecho de que al asumir la defensa de reivindicaciones específicas, claramente definidas y cuantificadas, su mandato delegado no corre el riesgo de ser abstracto e interpretativo, y por la misma razón, generalizado e independiente de los representados, como ocurre con los partidos políticos.

\section{Debilidades de las organizaciones sociales}

Las organizaciones de la sociedad civil están afectadas por debilidades que en muchas ocasiones se presentan como argumento para descalificarlas como instancias que representan intereses y voluntades colectivas ciudadanas.

Las organizaciones sociales de todas clases, en general, tienen muchas débiles, pero esas debilidades no las incapacitan para ser sujetos sociales que promueven el desarrollo y fortalecen la democracia.

Una de las principales debilidades de las organizaciones sociales es su alto grado de fragmentación y dispersión territorial y orgánico.

¿Cuál es la explicación de que se formen muchas organizaciones sociales con iguales objetivos en un mismo entorno barrial o rural?

Veamos: en las sociedades los individuos se encuentran ubicadosen relaciones de trabajo altamente diferenciadas y heterogéneas.

Hay obreros de la industria, del comercio, de los servicios, de la construcción, agrícola, empleados públicos y privados, desempleados, pequeños, medianos y grandes propietarios privados urbanos y rurales ubicados en todos los sectores de la producción.

Además, en los últimos años se ha producido una gran desalarización de la fuerza de trabajo que ha provocado que gran parte de la población económicamente activa se haya visto compelida a establecer relaciones de trabajo de tipo no capitalista, convirtiéndose en "trabajadores por cuenta propia", quienes han pasado a ejecutar las más variadas actividades artesanales, ambulatorias, 
etcétera, y a convertirse en una infinidad de micros propietarios, que desafían la clasificación de las hasta ahora conocidas taxonomías sociológicas.

Todas esas categorías ocupacionales tienden a organizarse de acuerdo a la defensa de sus objetivos particulares más inmediatos.

También está el hecho de que a esas variadas y combinadas relaciones de trabajo corresponden experiencias y percepciones diferentes de una misma realidad, a las que corresponden diversos grados de conciencia.

Pero también está la circunstancia de que los pobladores urbanos y rurales reciben informaciones y propuestas acerca de la realidad política y social provenientes de diversas fuentes ideológicas, y esas fuentes ideológicas tienen formas distintas de interpretar un mismo fenómeno social y, también, métodos y estrategias diferentes para solucionar un problema común.

No se debe olvidar tampoco, que los procesos de socialización que reciben los seres humanos no son siempre iguales y que ellos determinan tipos de personalidad y formas de comportamientos desiguales que tratan de imponer en las organizaciones a las que pertenecen.

Todos esos elementos se constituyen en factores que motivan a ciudadanos y ciudadanas a estar organizados pero separados.

Esa división es la causante de que, en general, las acciones que realizan las organizaciones sociales, destinadas a lograr el desarrollo comunitario y mejorar la calidad de vida de la gente no hayan sido trascendentes, en la medida trabajan aisladamente cada una en su microcosmo particular, sin concertar ni coordinar con otras organizaciones.

Pero también porque en su trabajo comunitario ha primado una concepción patemalista y asistencialista.

Una debilidad grande de las organizaciones sociales, sobre todo de las comunitarias o de base, es su carácter efímero. En efecto, según la investigación realizada por Tahira Vargas, el 35 por ciento de las organizaciones de base en Santo Domingo tenían dos años de existencia al momento de ser estudiadas, y el 32 por ciento tenía menos de cinco años de haber sido fundadas, o sea, que más del 65 
por ciento de las organizaciones de base tenía menos de cinco años de existencia. ${ }^{8}$

La explicación de que las organizaciones comunitarias sean tan pasajeras puede estar en las episódicas rupturas de los procesos económicos y políticos dominicanos y, con ello, en la falta de continuidad de los procesos de formación de los grupos sociales.

Un autor sostiene al respecto, que la multiplicidad organizativa de la sociedad civil que emerge a la caída del trujillismo no tuvo relación de continuidad con la sociedad civil de los años 70, pues la reestructuración autoritaria del balaguerismo cortó al proceso de formación de las clases y grupos populares urbanos como sujetos de acción política, reduciendo drásticamente sus espacios y formas de organización. ${ }^{9}$

Otro factor importante que ha limitado la posibilidad de que las organizaciones sociales tengan un bajo perfil público estriba en que no se han asumido como sector y carecen de un proyecto historico que las guíc a actuar unitariamente como grupo de presión y a entrar en proceso de negociación, concertación. coordinación y planificación de estrategias y acciones sociales y económicas con los demás agentes sociales del desarrollo.

En este aspecto la situación es circular en la medida en que tampoco existen mecanismos de los partidos. los ayuntamientos y otras instituciones públicas y privadas para articular sus planes, programas y proyectos con los objetivos, las iniciativas y los recursos de las organizaciones de la sociedad civil.

Es como si existiera una especie de tranque estructural que mantiene aislados y dispersos los agentes políticos y del desarrollo a escala nacional y local.

Sin embargo, de todos los agentes sociales que trabajan por el desarrollo local y comunitario para mejorar la calidad de vida de la gente, las organizaciones de la sociedad civil son las más indicadas para romper ese tranque y convocar y movilizar a los demás agentes

8 Tahira Vargas, Ob. cit. Pág. 52.

9 José Oviedo. La tradición autoritaria. Suplemento Realidad. Periódico El Siglo. Santo Domingo. 20 de julio de 1989. 
a coordinarse para planificar y ejecutar planes, programas y proyectos de desarrollo a escala local.

La mayoría de las organizaciones sociales están preparadas para convertirse en el eje aglutinante que convoque a los demás agentes a coordinarse para trabajar por el desarrollo a escala local.

Otras organizaciones lo que necesitan es cambiar su visión y su práctica, para adecuarse a los nuevos tiempos democráticos y participativos.

Estas últimas organizaciones, corporativas. comunitarias, populares, grupos de base, son tradicionales y reproducen el statu quo social, económico y cultural que crea la pobreza que dicen combatir.

Son instituciones que se caracterizan por desarrollar un tipo de gestión técnico-instrumental, es decir, verticalistas, impositivas, patrimonialistas, autoritarias, sin participación popular.

$\mathrm{Y}$ hoy lo que demanda la gente, los ciudadanos, las comunidades, son organizaciones democráticas y democratizadoras, preocupadas por producir cambios en la mentalidad, en los modos de vida. y en las relaciones sociales y de trabajo alienantes y reproductores de más pobreza.

Organizaciones que elaboren, planifiquen, decidan y ejecuten los proyectos mediante formas participativas que superen la tradicional división entre administradores y técnicos, por un lado, y población meta (campesinos, pobladores, marginados) por el otro lado.

Organizaciones que practiquen formas de trabajo y de organización social que construyan modelos o referentes culturales de autoestima y de relaciones entre iguales sociales.

Que faciliten la "autogestión", entendiendo por autogestión "formas de organización de las actividades sociales, tanto de tipo productivo, de servicios y administrativas, en las que las decisiones respecto de su conducción sean tomadas directamente por quienes participan en las mismas, sin la intervención de presiones ajenas al proceso". ${ }^{10}$

10 Martha Schteingart. Autogestión urbana y derechos ciudadanos. Revista Tercer Sector. Año II No. 6. Centro Doninicano de Organizaciones de Interés Social-CEDOIS-. Santo Domingo. Septiembre-Noviembre de 1991. Pág. 8. 


\section{Oposición a la participación comunitaria}

Para oponerse a la participación de las organizaciones comunitarias, se ha alegado que en la actual situación de debilidad económica esa participación sería un remedio peor que la enfermedad, pues abriría muchas demandas sociales imposibles de satisfacer.

Creo que sería todo lo contrario, es decir, que cuando las organizaciones comunitarias estén debida y oportunamente informada y tengan oportunidad de incidir en las políticas y estrategias que se formulen, no se sentirán ajenas a la política y a lo público, sino parte de ellos y ayudarán a establecer el orden de prioridad en que deben solucionarse los problemas y a buscar y aportar los recursos requeridos.

La participación de las organizaciones comunitarias en los procesos de toma de decisiones corregiría la desvinculación que existe entre los representantes con la ciudadanía, lo que ayudaría a superar la indiferencia de la ciudadanía local hacia las instituciones políticas.

Contribuiría también a superar la insuficiencia de comunicación que norma la relación de los representantes políticos con las y los ciudadanos.

En general, con contadas excepciones, las instituciones en las cuales se efectúa la representación política no tienen políticas ni prácticas informativas para que los ciudadanos se enteren de forma veraz, actualizada y oportuna de la gestión, de los planes, programas, proyectos de las mismas.

Pero a las organizaciones comunitarias les resulta relativamente fácil establecer canales de comunicación y retroalimentación informativa con los ciudadanos.

Además de su contacto directo con los pobladores, muchas organizaciones comunitarias, clubes, y ONGs, tienen promotores sociales, programas permanentes de encuentros, talleres, charlas, periódicos, boletines, revistas, hojas informativas, y otros medios a través de los cuales propician comunicaciones abiertas con los sectores populares, urbanos y campesinos, y los pondrían al servicio de las instituciones públicas. 
Las organizaciones comunitarias constituyen también un factor para el desarrollo local en la medida aportan trabajo voluntario, capacidad técnica, experiencia organizativa, recursos financieros y otros recursos que potenciarían la gestión municipal en caso de concertación y coordinación con los gobiernos locales.

Como acertadamente señala José Aracena, los municipios aumentarían el impacto de su acción y se constituirían en actores fuertes frente al Estado central, si concertaran con las organizaciones territoriales y las organizaciones de empresarios locales la elaboración y realización de planes concretos de desarrollo. ${ }^{11}$

\section{División municipal y participación social}

La ley de organización municipal afirma que la creación, la supresión, la consolidación y la modificación de municipios, así como sus límites y su designación, serán dispuestos por ley. (Art. 2).

Según el artículo 52 de la ley de Organización Municipal cada municipio se divide en Secciones. El artículo 45 de la misma ley declara que dentro de cada municipio pueden ser creados por ley uno o más Distritos Municipales.

Cada Distrito Municipal está presidido por una Junta Municipal, la cual formula un presupuesto y ejerce, en su Distrito, las mismas atribuciones que el ayuntamiento.

Ni la ley de Organización Municipal ni la ley de División Territorial son precisas respecto a la división y organización política y administrativa de los municipios.

La Ley de División Territorial (No. 5220), se circunscribe a dar una extensa relación de las provincias, los municipios, distritos municipales y secciones que tiene cada provincia.

Esta ley ni la de organización municipal establecen criterios geográficos, demográficos, económicos, administrativos o de participacion política para dividir los municipios en secciones y crear distritos municipales.

En relación con la participación social, las Juntas de los Distritos

11 José Arocena. Estado, descentralización e iniciativa local en Uruguay. En Políticas Sociales. Mujeres y Gobiemo Local. CIEPLAN. Santiago de Chile. 1992. Pág. 139. 
Municipales pudieran ser mecanismos de representación directa o casi directa de las organizaciones comunitarias y de base, pero no es así, pues las Juntas Municipales reproducen los mismos esquemas y prácticas excluyentes de los ayuntamientos, del Poder Ejecutivo, del Senado y la Cámara de Diputados.

Peor aún, las Juntas Municipales tienen menos legitimidad social que las instancias anteriormente mencionadas en tanto, contrario a éstos, sus representantes no son elegidos por el voto de los/as ciudadanos/as, sino que son designados por los ayuntamientos, predominando en la selección el favoritismo partidista o un intercambio de favores.

Uno de los efectos visibles de esa falta de criterios para crear municipios y para dividir estos en secciones y en distritos municipales es que afecta la participación política, pues crea circunscripciones electorales desiguales, en las que se elige la misma proporción de representantes con cantidades de votos diferentes.

Por ejemplo, en la región del Cibao, la provincia Puerto Plata, con una población, según el censo de 1993, de 261,485 habitantes, está dividida en ocho municipios, los cuales tendrán 44 regidores a partir de las elecciones municipales de 1998, en tanto que la provincia La Vega, con 344,721 habitantes, es decir, 83,236 habitantes más que la provincia Puerto Plata. tiene sólo cuatro municipios, los cuales tendrán 30 regidores a partir de 1998.

Es decir, que La Vega tiene 83,236 habitantes más que Puerto Plata, y por el descontrol poblacional, administrativo y territorial en la creación de municipios, La Vega tiene 14 regidores menos que Puerto Plata. Si se tratara de una simple operación aritmética La Vega debería tener 58 regidores a partir de 1998, es decir, 14 regidores más que Puerto Plata, no menos como ocurrirá en la realidad.

Ese ejercicio aritmético se puede hacer provincia por provincia y municipio por municipio, y en todos los casos las comparaciones resultarán enojosas o risibles, por ejemplo, tomando de nuevo a Puerto Plata, pero esta vez comparándola con San Cristóbal.

Según el censo de 1993, San Cristóbal tiene 420,820 habitantes, casi el doble que Puerto Plata, pero tendrá sólo 40 regidores, 4 menos que Puerto Plata. 
En relación con la representación municipal de síndicos y regidores, o Puerto Plata está sobrerepresentada, o La Vega y San Cristóbal están subrepresentadas.

En lo referente a los distritos municipales y las secciones, aunque las leyes no lo precisen, se puede hacer una interpretación del texto y determinar que la sección es una unidad geográfica y el distrito municipal una categoría administrativa, pero no política.

La Constitución y las leyes dejan a la libre determinación de los legisladores los fundamentos para formar municipios, distritos municipales y secciones.

Como es así. la elevación de ciudades y poblados a la categoría de provincias, municipios y distritos municipales por parte de los legisladores depende más de presiones y formas de clientelas políticas locales por diversos grados de favores, que de racionales y juiciosos criterios económicos, demográficos y de representación política.

Lo peor de todo es que la Constitución, la ley de Organización Municipal y la ley de División Territorial, en el aspecto de la división territorial, provincial y municipal, parece que obedecen a un espíritu o propósito no formulado de separación y fragmentación política y administrativa del territorio.

En los tres textos está ausente un esquema de coordinación interinstitucional, para articular políticas y estrategias de desarrollo a escalas regionales, provinciales y municipales.

\section{¿Qué es un barrio?}

Entre los grandes retrasos y limitaciones que tiene la ley de organización municipal está el hecho de que no dice nada de los barrios, que son las unidades territoriales que delimitan o dividen los asentamientos y agrupamientos urbanos.

Tampoco la ley de División Territorial, la No. 5920, que data de 1959, menciona los barrios.

Lo peor, es que en una reciente publicación de la Oficina Nacional de Estadística, en la cual supuestamente se actualiza la división territorial, se incluyen, definen y contabilizan las secciones 
y parajes rurales como unidades que componen la división políticoadministrativa del país, pero no se dice nada de los barrios. ${ }^{12}$

Los barrios son, sin embargo, las unidades geográficas y poblacionales que forman y definen el tejido y la configuración urbana de las ciudades, así como los procesos modernos de producción y comercialización económica. ${ }^{13}$

Los barrios, constituyen las unidades urbanas de carácter celular y entomo inmediato con los cuales la población tiene una relación cotidiana directa y son los referentes más generalizados de organización vecinal.

En cada barrio se forman asociaciones o juntas de vecinos, asî como otros tipos de organizaciones territoriales populares, que actúan como nuevas formas de agregación y de representación local de ciudadanos.

La intervención política, económica y social de esas organizaciones es cada vez mayor.

Muchas de esas organizaciones no sólo recogen, priorizan y demandan los principales problemas comunitarios convirtiéndolos en pliegos y programas reivindicativos locales, sino que incluso solucionan problemas colectivos ejecutando obras con sus propios esfuerzos y recursos, independientemente de las autoridades municipales.

Pero además, los barrios tienen un valor estratégico para orientar políticas poblacionales que inviertan la peligrosa tendencia de crecimiento de las ciudades hacia su periferia y su consiguiente encarecimiento de los servicios y equipamientos urbanos. ${ }^{14}$

12. Ver: División Territorial. República Dominicana 1995. Secretariado Técnico de la Presidencia. Oficina Nacional de Estadísticas. Santo Domingo, enero de 1995.

13 La palabra "barrio" se deriva del árabe barr (alrededor de una ciudad). Hasta el siglo XVI, barrio designa una aldea pequeña, dependiente de una localidad mayor. Después se utilizó como sinónimo de suburbio y con posterioridad se desarrolló como porción intema de una ciudad, significado que conserva todavia hoy en España y otros paises latinos. En muchos países latinoamericanos los barrios son exclusivamente los lugares donde habitan los pobres, conceptualmente separados de las urbanizaciones, donde habitan los ricos. (Grohmann, 25).

14 César Pérez. Propuesta de remodelación y mejoramiento de Villa Juana. En Política y Gestión Urbana en la Región del Caribe. Coalición para el habitat. Santo Domingo. 1997. Pág. 134. 
Los barrios deben ser, pues, reconocidos jurídicamente como las células de la división territorial, demográfica, política y administrativa del entomo urbano de los municipios. Las unidades básicas para la participación, la planeación y la ejecución de planes y programas municipales en el ámbito urbano del municipio.

\section{Niveles de la participación}

La participación popular no se da en abstracto, en el vacío, es necesario que existan mecanismos que la estimulen y la hagan posible.

Hay que tener en cuenta, además, que la participación de los sujetos no es del mismo grado, que no todos(as) los sujetos se integran a los procesos públicos y privados con la misma intensidad.

En consecuencia la participación y la representación son de diferentes niveles y categorías y se ejercen por medio de numerosos mecanismos.

La participación se puede ejercer a nivel de consulta, planificación, iniciativa, decisión, ejecución de acciones, control y fiscalización, rendición de cuentas, revocación de mandatos y otras formas.

La mayoría de estos mecanismos de participación tienen carácter consultivos y propositivos, es decir, que en ellos los ciudadanos y las organizaciones primarias tienen libertad y derecho para expresar opiniones, críticas, observaciones y propuestas en aspectos específicos, pero sin que estas opiniones o propuestas tengan categoría de decisión final.

Dicho en otras palabras, la existencia de la mayor parte de estos mecanismos participativos en una estructura política no obliga necesariamente a las autoridades a escoger y materializar en acciones las opiniones y propuestas en ellos planteadas, pero sí contribuye a que las decisiones tomadas sean las de mayor grado de consenso y aceptación social.

Una ventaja al respecto, es que muchos de estos mecanismos participativos pueden adoptarse y ponerse a funcionar de inmediato, por ejemplo, en la actual gestión de los ayuntamientos, pues un aspecto en el cual los ayuntamientos están en capacidad de ejercer 
la autonomía municipal es precisamente en el relacionado con la participación comunitaria.

Por resolución municipal, se puede establecer una estructura del gobiemo local que facilite la participación de las organizaciones comunitarias en los procesos de toma de decisiones de la gestión municipal.

\section{Factores que limitan la participación popular}

En numerosos talleres que he realizado en todo el país acerca de la participación he recuperado una serie de factores que los(as) dominicanos(as) citan como obstáculos que limitan y a veces impiden la participación comunitaria.

Entre los obstáculos señalados están:

1) porque en su mayoría, los ciudadanos(as) no están organizados;

2) por el desconocimiento generalizado de la población de sus derechos y deberes políticos y ciudadanos, debido en parte al bajo grado de escolaridad de la mayoría y a la falta de información por parte de las instituciones y las autoridades correspondientes;

3) por la división y dispersión de las organizaciones comunitarias o de base;

4) porque las organizaciones sociales existentes no se han planteado la participación o intervención en la gestión político/pública como uno de sus objetivos;

5) por la centralización de poder y de toma de decisiones;

6) por la sectarización partidista y la monopolización de la actividad política;

7) por la cultura y la tradición autoritaria y excluyente de la sociedad y el Estado dominicano;

8) por la debilidad institucional del sistema político;

9) por el excesivo burocratismo del sistema político y administrativo;

10) por apatía e indiferencia de la sociedad hacia la política; 
11) por frustración debido a las promesas incumplidas (demagogia política), y a las experiencias negativas ante los fracasos individuales y colectivos de los ciudadanos y sus organizaciones.

12) porque la política está arropada por la práctica del clientelismo político;

13) porque los ciudadanos(as) temen contraer compromisos políti$\cos$ (falta de responsabilidad ciudadana).

En síntesis, los aspectos más relevantes que obstaculizan la participación popular son:

a) La cultura política autoritaria ha dado como consecuencia actitudes y prácticas caudillistas y de clientela a escala local que tienden a rechazar la participación comunitaria.

b) El autoritarismo y el caudillismo ha impedido desarrollar una tradición de diálogo y debate político a escala local limitando con ello el flujo de informaciones y la educación política de los diferentes sectores y actores locales.

c) Muchas de las organizaciones de base son de formación reciente (3-5 años) y aún no han completado sus procesos de definición de objetivos, son institucionalmente débiles y sus dirigentes y miembros(as) no poseen experiencia concreta de vinculación y trabajo coordinado con las autoridades.

d) La dispersion, fragmentación y limitados niveles de coordinación que existe entre las organizaciones de la sociedad civil es un freno para desarrollar un plan de ampliación y fortalecimiento de la participación social a nivel municipal en el corto plazo.

e) Direcciones de los partidos políticos, sectores del empresariado y de la cúpula de la Iglesia Católica que no reconocen la autoorganización ciudadana en organizaciones de base y no aceptan estas formas organizativas como interlocutoras frente al Estado.

f) Hay oposición de muchos síndicos y regidores a reconocer las organizaciones comunitarias por considerar que: a) la participación y representación para decidir los asuntos políticos es exclusiva de los partidos; b) consideran que las organizaciones 
de base y ONGs no son representativas; c) tienen temor de la participación social, pues creen que ésta le hará perder su cuota de poder.

g) Hay muchas propuestas de participación de las organizaciones comunitarias en los mecanismos políticos de toma de decisiones, pero están dispersas, lo que limita la posibilidad de ser conocidas y analizadas por los partidos políticos y por los congresistas.

h) Existe mucha confusión por parte de las autoridades municipales acerca de las propuestas de participación de las organizaciones comunitarias en la gestión municipal, pues en las mismas no han sido definida con claridad las competencias, atribuciones y funciones que estas organizaciones desempeñarían, si su tipo de relación con las Salas Capitulares y las Sindicaturas, dando como resultado que tanto los dirigentes de los partidos como las autoridades tengan la incorrecta percepción que de lo que se trata es de sustituirlos en su rol institucional.

Una autora, la profesora Luz A. Vega, de la Escuela Graduada de Trabajo Social de la Universidad de Puerto Rico, al conceptualizar la participación popular establece que ésta está condicionada por factores sociales, políticos, económicos y culturales, entre ellos: ${ }^{15}$

i) la burocratización y centralización de los sistemas, y el desconocimiento de sus procesos intemos por parte del ciudadano común, sumado a la carencia de mecanismos de participación sistematizados;

ii) un sentido de impotencia colectiva generalizada que lleva a concluir que "todo está decidido y nada cambiará";

iii) el temor a represalias cuando se adoptan posiciones contrarias a las oficialistas;

iv) costos de la participación para los centros de poder y los

15 Luz A. Vega Rodríguez. Participación popular: marco conceptual. En Quiénes hacen ciudad? Ambiente urbano y participación popular: Cuba, Puerto Rico, República Dominicana. Edición de la Sociedad Interamericana de Planificación -SIAP-. Cuenca. Ecuador. 1997. Pág. 96. 
dirigentes, pues implica alterar patrones de comportamiento mantenidos por muchos tiempo; la participación demanda redistribución del poder; y

v) para los que quieren incorporarse a los procesos decisionales. implica el abandono de posiciones comodas de pasividad e indiferencia y asumir las responsabilidades propias de la participación.

\section{Factores que favorecen la participación popular}

Como vimos, en la realidad social y política existen y se presentan situaciones y condiciones que obstaculizan la participación popular; de la misma manera, existen y se presentan otras que la facilitan. Sin pretender ser exhaustivos, listamos algunos factores que facilitan la participación social, la mayoría de ellos recuperados en talleres y seminarios a los cuales he asistido como facilitador.

1) Tener información oportuna y veraz de las iniciativas y los procesos políticos;

2) existencia de buena voluntad política por parte de las autoridades;

3) contar con una actitud de apertura y diálogo de parte de todos los sujetos sociales a nivel público y privado;

4) conocer los derechos y deberes políticos y ciudadanos;

5) la existencia de principios, reglas y leyes claras y que no sean injustas ni discriminatorias;

6) instituciones que se rijan por reglas y principios democráticos;

7) el ejercicio de la democracia a todos los niveles de la vida pública y privada;

8) la organización de los ciudadanos(as) en organizaciones comunitarias;

9) respeto a los derechos individuales y colectivos consagrados por la Constitución;

10) la tolerancia y el respeto a las opiniones ajenas;

11) la existencia de mecanismos de consulta y de decisión como asambleas, encuentros y conversatorios, foros y talleres, elecciones; 
12) desconcentración territorial de recursos y descentralización política y administrativa.

Otros factores que en el caso dominicano favorecen la participación o intervención popular en los asuntos y las decisiones políticas son:

a) El trabajo permanente de educación a nivel nacional de muchas ONGs ha contribuido a que la cultura política tradicional de la sociedad vaya cambiando y que la ciudadanía comience a cuestionar los comportamientos autoritarios y excluyentes de las autoridades y al interior de las propias organizaciones comunitarias.

b) Por la competencia electoral de los partidos, el trabajo de las ONGs y la difusión de los medios de comunicacion, ha estado surgiendo una conciencia ciudadana del valor del pluralismo político y el respeto a las opiniones de los demás sujetos.

c) Las organizaciones populares y los movimientos sociales, así como las instituciones del Estado han estado pasando paulatinamente de la confrontación a la oposición/diálogo/negociación, proceso en el cual ambas partes se reconocen como interlocutores.

d) Los partidos políticos mayoritarios, que tienen el monopolio de la representación política, reconocieron en los programas de gobiemos presentados en las elecciones presidenciales de 1996 , la importancia de las organizaciones de base y ONGs, y su derecho a participar en la gestión gubernamental.

e) Existe un reconocimiento, limitado, a las juntas de vecinos, por parte del Ayuntamiento del Distrito Nacional. Ese reconocimiento puede ser ampliado a otras organizaciones sociales y generalizado a todos los municipios, pues está normado por un reglamento sencillo que establece las relaciones entre las Juntas de Vecinos y el ayuntamiento.

f) Muchas de las organizaciones comunitarias o de base, populares y ONGs son reconocidas y valoradas positivamente por la ciudadanía, por su trabajo educativo, reivindicativo de los 
derechos ciudadanos, ecologista, de mejoramiento urbanorural y de desarrollo comunitario.

g) Varios ayuntamientos han establecido acuerdos de colaboración, trabajo y coordinación con ONGs y organizaciones comunitarias para buscar de manera conjunta solución a los problemas municipales, to que ha redundado en beneficio de la participación en la medida se han abierto procesos de diálogos. retroalimentación informativa y se han ensayado algunos mecanismos de consulta como Foros y Cabildos Abiertos. Esto puede ser emulado por otros municipios.

h) Un precedente importante del punto anterior, en la elaboración por parte del Centro Padre Juan Montalvo, de un Borrador/ Propuesta de Estatuto de Reconocimiento y relación entre las Organizaciones de Base y el Ayuntamiento del Distrito Nacional. Dicho Borrador contiene los requisitos que deben cumplir las organizaciones comunitarias para ser inscritas en el Registro Municipal de Organizaciones Locales. los derechos y beneficios que para las organizaciones confiere el ser reconocida por el Registro, los deberes y las obligaciones y los mecanismos mixtos de participación.

i) El X Congreso Nacional de Municipios adoptó una propuesta de reformar la Ley de Organización Municipal en la cual se establece una nueva estructura para los ayuntamientos. La nueva estructura incluye varios de los mecanismos participativos, como los Consejos Consultivos Municipales, propuestos por las organizaciones sociales. La propuesta fue convertida en proyecto de ley por la Liga Municipal Dominicana.

j) Los programas de gobiemo de los partidos políticos tienen también propuestas de establecer en los ayuntamientos Consejos Consultivos Municipales y otras formas de intervención de las organizaciones sociales en la toma de decisiones, está también contenida en varios de los programas de gobiemo de los partidos que concurrieron a las elecciones presidenciales de 1996.

Todos esos factores constituyen recursos en beneficio de la 
sociedad civil y de las organizaciones comunitarias o de base para potenciar sus esfuerzos, trabajos y propuestas para construir un sistema mixto de participación y representación social y política.

Ahora bien, quede claro que esos elementos no son los que tienen primacía, los dominantes en la cultura y el ejercicio práctico de la política, al contrario, la mayor parte de ellos son aún meras referencias orientadoras de por donde continuar insistiendo y trabajando para lograr la democratización de la sociedad y el Estado dominicanos y hacerlos más participativos.

\section{Qué hacer?}

Lo primero que se requiere es que las comunidades estén organizadas en grupos o identidades comunitarias o de base; que estos grupos estén fortalecidos ins'itucionalmente, es decir, provistas de sus estatutos con sus fines, objetivos, y estructura orgánica, claramente definidos.

Las organizaciones de base deben tener también una residencia o lugar de ubicación, una directiva con sus correspondientes cargos y los nombres de las personas que ocupan esos cargos, celebrar reuniones perí́dicas, llevar actas de las reuniones, informar por algún medio sus actividades y tener comunicación permanente con la comunidad y con las autoridades locales.

La participación popular, para ser lograda, requiere además cambios, reformas o modificaciones políticas, jurídicas e instituciones formales y de gestion.

Entre las reformas políticas e institucionales necesarias, hay que destacar, fundamentalmente, la de la ley de organización municipal, la ley de división y organización territorial, la ley de ingresos y gastos públicos, las leyes sobre planificación y otras relacionadas con los municipios.

Es necesario, además, crear otras leyes, como una ley de participación política y social. Una ley de descentralización es clave, pues hay que descentralizar o transferir a los ayuntamientos un conjunto de competencias, recursos financieros y poder político actualmente centralizados por el gobierno central. 
La descentralización para lograr fortalecer los ayuntamientos y convertirlos en eficaces coordinadores y promotores del desarrollo local necesita la redistribución de las asignaciones del Presupuesto Nacional, para incrementar de manera progresiva la coparticipación de los ayuntamientos en las recaudaciones fiscales y en las asignaciones de los gastos e inversiones sociales.

El proceso requiere repensar el concepto tradicional de municipio, para darle una nueva definición y considerarlo como un facilitador o coordinador del desarrollo local, para lo cual canaliza la participación de todos los agentes sociales locales.

Para que el proceso sea coherente y realmente participativo, se requiere también aprobar una nueva ley electoral, que defina los sujetos electorales y los niveles y mecanismos de representación y participación.

Para lograr una real participación popular a nivel municipal, hay que mantener separadas las elecciones municipales de las presidenciales y las congresionales, pero no basta sólo con eso; hay que construir, también, una estructura municipal en la que participen representantes de los partidos, de los movimientos municipales, de las organizaciones locales reconocida por un Registro Municipal.

Elecciones municipales verdaderamente participativas y democráticas requerían de por lo menos tres fases o momentos:

1) Fase de presentación de candidaturas a síndico y regidores o representantes de la Asamblea Municipal. La presentación de candidatos, así como la nominación y elección posterior, se debe hacer por demarcación o circunscripción específica, geográficamente delimitada, en la ciudad y la zona rural.

En esta fase, todos, absolutamente todos los ciudadanos tienen el derecho y la oportunidad de presentar y ser presentado como posible candidato, por los partidos, por los mismos ciudadanos, así como por las organizaciones populares reconocidas por el Registro Municipal.

2) Fase de nominación de los candidatos presentados. Como los presentados pueden resultar muchos, mediante elecciones primarias abiertas por circunscripción se escogen los candidatos a 
ser nominados. La Ley electoral puede establecer algunos criterios para la escogencia de los nominados (por ciento de los votantes de cada circunscripción, etc.).

3) Elecciones de regidores o representantes a la Asamblea Municipal. Luego de la nominación de los candidatos por circunscripción, se elige por votación directa y secreta, el regidor o representante de dicha circunscripción, por el período que determine la ley electoral.

Lo ideal sería construir un sistema político en el cual a nivel de los gobiernos municipales la participación y representación social y política se canalizara y se ejerciera vía las organizaciones locales.

Es decir, modelos de participación municipal sin intervención de los partidos políticos nacionales. Pero una propuesta semejante en la actualidad no tiene ninguna posibilidad, por tanto, no es viable.

Al dar respuesta a la pregunta de cómo lograr la participación de todos los miembros de la sociedad en la toma de decisiones y la ejecución de las mismas, el sacerdote jesuíta Jorge Cela plantea nueve condiciones para lograrlo. ${ }^{16}$

Transcribimos a continuación las nueve condiciones descritas por Cela:

- Lo primero que se requiere es una adecuada institucionalización a través de mecanismos y reglas de juego universalmente aceptadas y claramente establecidas.

- Lo segundo que se requiere es una descentralización, de manera que las decisiones se tomen en el ámbito a que pertenecen.

- Lo tercero es la colegiación, es decir, que la toma de decisiones a todos los niveles debe ser un proceso colectivo en el que estarán presentes los representantes de todas las identidades implicadas.

- Lo cuarto es la democratización de las instituciones participantes de forma que sus representantes sean realmente portavoces de la opinión del colectivo.

16 Jorge Cela. Participación de la sociedad civil: Evaluación de las potencialidades dominicanas. Programa de las Naciones Unidas para el Desarrollo. Mimeo. Santo Domingo. 1993. Pág. 6. 
- Lo quinto es que para ello es necesario una información completa y clara que permita a todos una opinión inteligente.

- Lo sexto es atender a las minorías disidentes de forma que no sean simplemente eliminadas por el voto mayoritario.

- Lo séptimo es la creación de mecanismos de retroalimentación y consulta amplia.

- Lo octavo es la creación de mecanismos para la sustitución (revocación) de representantes cuando éstos pierden su calidad de tales.

- Lo noveno es la elaboración de formas de resolución de conflictos claros y previamente aceptados.

\section{Modelo de estructura municipal con participación popular:}

Para contribuir con la reflexión y el debate sobre la participacion popular y de las organizaciones sociales en los mecanismos públicos de toma de decisiones, especialmente en el régimen y la gestión municipal, presento algunas propuestas para el debate.

1.- Establecer constitucionalmente que los municipios constituyen la unidad política primaria de la organización nacional, con personalidad jurídica, territorio y recursos propios. Que son autónomos, populares, participativos y democráticos. Que la autonomía de los municipios se extiende a:

- La elección de sus autoridades

- Su gestión política y administrativa

- La capacidad para crear y recaudar los recursos para cumplir con sus funciones.

- La capacidad para elaborar, aprobar y ejecutar planes de desarrollo municipales.

- La capacidad para coordinar las relaciones políticas de los diversos actores y sujetos locales.

2.- Establecer como criterio general para formar un municipio un territorio con una población mayor de 10 mil habitantes, que tenga un centro urbano con una población mínima de 3 mil habitantes, y con capacidad productiva para generar ingresos 
monetarios que le permita cubrir los gastos burocráticos. Es decir, que todo ayuntamiento, deberá cubrir con recursos generados internamente los gastos de personal.

3.- Para facilitar la participación ciudadana, la coordinación comunitaria y vecinal y la canalización de las demandas sociales, cada municipio será dividido en Distritos Municipales (urbanos y rurales) y a su vez los Distritos Municipales se dividirán en Barrios (en la zona urbana) y en Secciones (en la zona rural). Con los barrios en las ciudades y las secciones en las zonas rurales se formarán circunscripciones en las cuales se instituirán Consejos Zonales Locales, para la representación política local, la planificación del desarrollo a escala local y la desconcentración y descentralización administrativa municipal.

4.- La estructura política del Gobierno Municipal estará constituido por una Asamblea o Concejo Municipal, también llamada Sala Capitular Municipal, que será el órgano legislativo municipal y tendrá carácter normativo, legislativo y resolutivo en asuntos concernientes a todo el territorio municipal y ejercerá fiscalización y control del Ejecutivo Municipal, función que corresponde al Síndico.

5.- Además del Concejo de Regidores y de la Sindicatura que es el organo ejecutivo, la estructura política de los ayuntamientos municipales tendrán un Concejo Consultivo, que es un organismo mixto integrado por representantes de las organizaciones sociales locales y autoridades locales y que tendrá la misıón de actuar como organismo de consulta de la Asamblea de Regidores y de la Sindicatura.

6.- Los regidores serán elegidos en representación de circunscripciones poblacionales que coincidan con números determinados de Barrios en las ciudades, y de Secciones en las zonas rurales.

7.- Como se trata de lograr una combinación entre representación y participación, de modo que se complementen, las circunscripciones electorales deben tener sus respectivas Asambleas de Rendición de Cuentas con poder resolutivo en aspectos específicos, para evitar la separación absoluta entre los representantes locales de las salas capitulares y sus representados. 
En dichas asambleas los regidores tendrán la obligación de reunirse periódicamente con los ciudadanos de sus circunscripciones para rendirles cuentas de su trabajo, de manera que la relación no sea sólo de carácter electoral, como es ahora, sino permanente.

De esta manera, habrá una mayor fluidez entre representantes y representados, por cuanto se logrará una permanente interación colectiva, informativa, de discusión y de construcción y canalización de propuestas, pues en estas asambleas, los regidores recibirán las demandas y peticiones de solución de los problemas comunitarios de las comunidades que representan.

8.- Los gobiemos municipales tienen el deber de facilitar y promover la organización ciudadana en asociaciones de base, juntas de vecinos, comités de cuadra, organizaciones populares, etc., para lo cual consignarán en sus presupuestos una partida anual, para facilitar a los ciudadanos y a las organizaciones comunitarias informaciones, asesoría, recursos y asistencia técnica e institucional.

9.- Cada ayuntamiento tendrá un Registro de Organizaciones Locales, para inscribir y otorgar reconocimiento municipal a las organizaciones populares locales que cumplan o llenen los requisitos de membresía, objetivos e institucionalización mínimos indispensables. El Reconocimiento Jurídico Municipal confiere a las organizaciones que lo obtengan capacidad de representación ciudadana en el ámbito municipal.

10.-Por Resolución Municipal se consignará derecho de Iniciativa Municipal a las organizaciones reconocidas en el Registro Municipal de Organizaciones Locales. Se establecerá que la iniciativa, para ser considerada debe ser respaldada por la firma 0 adhesión de, por ejemplo, mil ciudadanos del municipio.

Este derecho de iniciativa debe ser extendido también a los ciudadanos de manera particular, es decir, aunque no estén organizados, siempre que reúnan las firmas o adhesiones necesarias establecidas.

La Iniciativa Municipal da derecho a los ciudadanos a presentar a las Salas Capitulares proyectos de resoluciones o leyes municipales. 
11.-También por resolución municipal se establecerá que las organizaciones y los ciudadanos de un municipio, después de llenar los requisitos que se establezcan, tienen derecho de presentar petición de veto o derogación de resoluciones municipales consideradas antipopulares a dañinas al espacio y a los intereses comunitarios.

12.-Se establecerá que además de las elecciones para escoger las autoridades municipales, son mecanismos de participación popular: los Plebiscitos Municipales, la Consulta Popular Municipal, los Cabildos Abiertos, la Iniciativa Popular y las Asambleas de Rendición de Cuentas.

Los Plebiscitos municipales son mecanismos en los cuales se someten a votación, para que sea la ciudadanía quien decida, asuntos de interés general o estratégico. La opinión mayoritaria expresada en ellos constituye un mandato imperativo para los concejos de regidores y los síndicos.

La Consulta Popular es un mecanismo de carácter consultivo mediante la cual los concejos de regidores recaban la opinión de la ciudadanía sobre asuntos importantes antes de tomar una decisión al respecto. La Consulta Popularno es resolutiva como el Plebiscito, es decir, la opinión mayoritaria expresada en ella no constituye un mandato imperativo, sino una opinión que enriquece las propias opiniones de los regidores.

13.-Los Plebiscitos y la Consulta Popular pueden ser solicitados por grupos de ciudadanos en una proporción correspondiente al uno por ciento (1\%) de los inscritos en el Registro Municipal Electoral. También pueden ser solicitados por el pleno del Concejo Municipal.

14.-Para la elaboración del Presupuesto Municipal la estructura municipal constará con Talleres de Planificación Zonal, mecanismos técnicos en los que estarán representados delegados de los Concejos Zonales Locales.

Estos Talleres o Comités de Planificación Zonales, estarán integrados por equipos interdisciplinarios de técnicos y por ciudadanos, y serán los responsables de determinar los problemas locales y de fijar las prioridades de los mismos. 
Los diagnósticos de los Talleres o Comités de Planificación Zonales serán los insumos básicos para la elaboración del Presupuesto Municipal, cuyas decisiones finales, en relación con las inversiones y los gastos en servicios colectivos municipales, estarán condicionadas por la escasez y la limitación de los ingresos.

\section{Acciones para promover la cuestión municipal}

Existen en el país muchas propuestas de participación social y popular en el sistema político, pero la mayoría de esas propuestas carecen de estrategias de cómo promoverlas y darlas a conocer para su posible aceptación. ${ }^{17}$

A continuación describo algunas acciones que podrían ser ejecutadas para avanzar en la promoción y posterior aceptación y aprobación de un modelo de gestión municipal con participación popular o comunitaria.

1.- Desarrollar una campaña de información y sensibilización nacional sobre la importancia que tienen las organizaciones de base en el fortalecimiento de la sociedad civil para el desarrollo de la democracia y, en consecuencia, la necesidad que hay de reconocerlas formalmente dotándolas de derechos y deberes, para que sean sujetos de participación en la gestión gubernamental.

2.- Incluir en la campaña de información y sensibilización la promoción del Registro Municipal de Organizaciones Locales, los Cabildos Abiertos y los Consejos Consultivos Municipales como los mecanismos consultivos, de asesoría y de participación de las comunidades para la toma de decisiones a escala local, y difundir que estos mecanismos pueden ser establecidos por los ayuntamientos por resoluciones municipales, sin la

17 Un precedente importante en la sociedad dominicana de presentación de una propuesta integral de reforma del sistema político en su conjunto, acompañada de un plan estratégico de cómo lograrlo, fue establecido por el Instituto Tecnológico de Santo Domingo-Intec-, al presentar "Una Estrategia para la Viabilidad de la Reforma Política". Ver Revista Ciencia y Sociedad. Volumen XXII. No. 1. Enero-Marzo de 1997. 
obligación de esperar una reforma a la ley de organización municipal.

3.- Para coordinar y dar seguimiento a la campaña de información y sensibilización es conveniente formar un Comité Coordinador integrado por representantes de los partidos políticos, organizaciones comunitarias, de la Liga Municipal, universidades, ONGs, y los ayuntamientos.

4.- Promover la formación de Comités Municipales que desde la sociedad civil promuevan las propuestas de Registros Municipales de Organizaciones Locales, Cabildos Abiertos, Consejos Consultivos Municipales y otras.

5.- Desarrollar un programa nacional de charlas, seminarios, foros y talleres municipales que aborden la discusión y elaboración de propuestas sobre los Registros Municipales de Organizaciones de Base, Cabildos Abiertos y Consejos Consultivos Municipales, Consultas, Plebiscitos, Referendum municipales y otras propuestas de participación social en el régimen municipal.

6.- Exhortar y solicitar a los partidos políticos que organicen talleres u otras actividades en las cuales sus miembros(as) conozcan, analicen y tomen acuerdos acerca de las diversas propuestas de participación comunitaria. En estas actividades deben tomar parte los legisladores, síndicos y regidores de cada partido.

7.- Determinar las organizaciones de base y ONGs existentes en cada municipio, su ubicación, estructura, membresía, objetivos, y condiciones de existencia, para solicitar que sean reconocidas por los ayuntamientos e inscritas en Registros Municipales de Organizaciones de Base.

8.- Realizar un Inventario de los ayuntamientos que estén de acuerdo en establecer Registros Municipales de Organizaciones de Base, Cabildos Abiertos, Consejos Consultivos Municipales, Consulta Popular, Plebiscitos, Referendum municipales y cualquier otras propuestas de participación popular, y estimularlos a crear, a manera de ensayo, algunos de estos mecanismos por resolución municipal, para presentarlos como modelos a 
emular por otros ayuntamientos.

9.- Inventariar también los ayuntamientos que se oponen a establecer en su estructura orgánica estos mecanismos de participación popular y determinar las causas de tal oposición, para elaborar hacia los mismos un plan de sensibilización y convencimiento de los beneficios que tendrían los municipios con la existencia de esos mecanismos.

10.-Identificar diputados y senadores que estén de acuerdo con la reforma del régimen municipal y con la ampliación de las estructuras representativas y participativas de los ayuntamientos, para coordinar con ellos actividades de promoción y apoyo a dicha reforma.

11.-Solicitar a la Liga Municipal, a la Comisión Presidencial para la Reforma y Modernización del Estado y al PNUD que en conjunto coordinen un plan nacional de discusión del proyecto de la Liga Municipal de reforma a la ley de organización municipal, para su enriquecimiento y ampliación. 


\section{BIBLIOGRAFIA}

CARDENAS GARCIA, Jaime F. Crisis de legitimidad y democracia interna de los partidos políticos. Fondo de Cultura Economica. México 1992.

CELA, Jorge. Participación de la sociedad civil: Evaluación de las potencialidades dominicanas. Programa de las Naciones Unidas para el Desarrollo. Mimeo. Santo Domingo. 1993.

CENTRO DE ESTUDIOS SOCIALES P. JUAN MONTALVO S.J. Borrador/Propuesta Estatuto de Reconocimiento y Relación entre las Organizaciones de Base y el Ayuntamiento del Distrito Nacional. Santo Domingo. 1996.

CENTRO DE PLANIFICACION Y ACCION ECUMENICA CEPAE- Informe Final del Proyecto Fortalecimiento del Poder Local y Participación Comunitaria. Mimeo. Santo Domingo. 1996.

COALICION PARA EL HABITAT. Política y Gestion Urbana en la Región del Caribe. Editora Taller. Santo Domingo. 1997.

COLLADO, Faustino. Legislación Municipal. Relación, Clasificación y Síntesis: Ley 3455 de Organización Municipal. Unión de Vecinos Activos -UVA- Santo Domingo. 1997.

COMISION PRESIDENCIAL PARA LA REFORMA Y MODERNIZACION DEL ESTADO. Ante Proyecto de Modificación a la Ley Electoral No. 5884. Junta Central Electoral. Santo Domingo. 1997.

DORE CABRAL, Carlos. "Los dominicanos participan políticamente más que los haitianos". Rumbo No. 96. Santo Domingo. 4 de diciembre de 1995 .

FIALLO BILLINI, José Antinoe. Nacionalismo y liberalismo: Recuperación de su pensamiento y su organización para la construcción de una estrategia popular. Mimeo. Universidad Autónoma de Santo Domingo. 1995.

FUNDACION FRIEDRICH EBERT. Sistemas Electorales y Representación Política en Latinoamérica. Volumen No. 1. Madrid. 1986.

HERNANDEZ, Pedro A. La Gestión de los Ayuntamientos de 
Luperón y Guananico (Lecciones para los Municipios Dominicanos). Programa de Desarrollo Provincial. Puerto Plata. 1997.

HOLA, Eugenia y PISCHEDDA, Gabriela. Mujeres, poder y política: nuevas tensiones para viejas estructuras. Centro de Estudios de la Mujer. Santiago de Chile. [s. f.]

IANNI, Vanna. Una mirada a la cultura política dominante. El Siglo. Santo Domingo. 8 de marzo de 1990.

INSTITUTO TECNOLOGICO DE SANTO DOMINGO -INTECUna Estrategia para la Viabilidad de la Reforma Política. Ciencia y Sociedad. Volumen XXII. No. 1. Enero-Marzo de 1997.

LENK, Kur y NEUMAN, Frank. Teoría y sociología crítica de los partidos políticos Editorial Anagrama. Barcelona, España. 1980.

OFICINA NACIONAL DE ADMINISTRACION Y PERSONAL. Constitución de la República Secretariado Técnico de la Presidencia. Santo Domingo. 1996.

OFICINA NACIONAL DE ESTADISTICAS: División Territorial. República Dominicana 1995. Secretariado Técnico de la Presidencia. Santo Domingo. 1995.

OVIEDO, José. "La tradición autoritaria". Suplemento Realidad. El Siglo. Santo Domingo. 20 de julio de 1989.

PEREZ, César y ARTILES, Leopoldo. Movimientos Sociales Dominicanos. Identidad y Dilemas. Instituto Tecnológico de Santo domingo -INTEC- Santo Domingo. 1992.

RACZYNSKI, Dagmar y SERRANO, Claudia. Políticas Sociales, Mujeres y gobierno local. CIEPLAN. Santiago de Chile. 1992.

SCHTEINGART, Martha. Autogestion urbana y derechos ciudadanos. Tercer Sector. Año II, NO. 6. Centro Dominicano de Organizaciones de Interés Social -CEDOIS-. Santo Domingo. Septiembre-Noviembre de 1991.

SOCIEDAD INTERAMERICANA DE PLANIFICACION. Quiénes hacen ciudad? Ambiente urbano y participación popular: Cuba, Puerto Rico, República Dominicana. Cuenca, Ecuador. 1997. 
VARGAS, Tahira. Las organizaciones de Base en Santo Domingo.

Centro de Estudios P. Juan Montalvo, S.J. Santo Domingo. 1994. 